\title{
Umbrales de transparencia en la imagen producida por artefactos de registro mecánico de la realidad*
}

\author{
Thresholds of transparency in the image produced \\ by mechanical recording of reality
}

ALBERTO MURCIA**

\begin{abstract}
Resumen: En este artículo se revisa la hipótesis sobre la transparencia de las imágenes de Kendall Walton y sus diferentes críticas. Propongo que la imagen fotográfico-cinematográfica solo puede ser potencialmente transparente. Debería, así, hablarse de grados de transparencia. La transparencia de la imagen se divide en umbrales que dependen de la fase de producción en la que esté. De esta forma tenemos transparencia en el registro, de representación, de enunciación y epistémica.

Palabras clave: transparencia; percepción; imaginación; ver como; ficción; edición.
\end{abstract}

\begin{abstract}
In this article, it is questioned Kendall Walton's claims about transparency. It is claiming that photographic-cinematographic image might only be transparent potentially, and we should talk about degrees of transparency. The threshold divides the image transparency, which depends on the timing of production of the image. Thus, there is recording transparency, transparency of representation, transparency of utterance, and epistemic transparency.

Keywords: transparency; perception; imagining; seeing as; fiction; editing.
\end{abstract}

Cuando se dice que algo es transparente nos referirnos a que se puede percibir a través de ese objeto. De manera análoga, se asegura que la imagen producida mediante artefactos de registro mecánico de la realidad es transparente. Pero pese a su fiabilidad informacional y semejanza con el modelo las imágenes fotográfico-cinematográficas ${ }^{1}$ no son plenamente transparentes, como Kendall Walton sostiene, aunque tampoco totalmente opacas, como defienden sus críticos.

Toda imagen permite cierta transparencia con el modelo que depende de en qué momento se esté en la producción de la imagen y de cómo se conserva la relación informacional desde el modelo a la representación. Mientras que la imagen es potencialmente transparente al registrarse, al editarse e introducirla en una ficción cinematográfica las

Fecha de recepción: 19/01/2015. Fecha de aceptación: 04/11/2015.

* Agradezco enormemente las conversaciones con Fernando Broncano y Jesús Vega Encabo sin las que no hubiese sido posible afinar ciertos aspectos de esta investigación. También agradezco las objeciones y notas aportadas por los revisores/as anónimos/as que trataron el texto.

** Investigador en la Universidad Carlos III. Contacto: albertomurcia79@gmail.com

1 Mientras no se especifique lo contrario, el término imagen refiere a las imágenes producidas por artefactos mecánicos de captación de la realidad; esto es, por lo general, las imágenes fotográfico-cinematográficas. 
condiciones que permitirían afirmar que sigue siendo transparente deben ser diferentes: no es lo mismo que se vea al actor Humphrey Bogart a que le percibamos como si fuese Rick, el dueño del bar de Casablanca.

Por lo general, cuando se habla de transparencia en el contexto de la imagen se suele entender este concepto exclusivamente como transparencia epistémica. No es el caso de este artículo en el que transparencia es sinónimo de transparencia perceptual ${ }^{2}$. Mi objetivo consiste en defender que las imágenes pueden ponernos en contacto perceptual con el modelo, y a ese contacto perceptual es a lo que llamamos transparencia. Sin embargo, dado que la imagen puede ser tratada desde su captación hasta su exposición, el término transparencia no puede ser utilizado de la misma forma. Por esta razón, considero que el proceso de producción de la imagen se puede dividir en distintos umbrales que marcan diferencias en el sentido del término transparencia. De esta manera tendríamos, transparencia en el registro, de representación, de enunciación y epistémica. La opacidad de la imagen también está relacionada con estos umbrales de producción de la imagen.

El problema que aquí se expone se encuadra dentro de dos discusiones filosóficas más extensas. Por un lado, ¿son «realistas» los medios de reproducción mecánica de la realidad? $\left(\right.$ Gaut, 1997) ${ }^{3}$.Por otra, ¿cuál es la relación entre la imagen y la imaginación? (Walton, 1980, 1990, 2008).

Sobre el realismo del medio cabe preguntarse ¿cuándo se ve un imagen estamos literalmente ante el modelo que representa esa imagen? (Bazin, 2004; Sesonske, 1978). De otro modo ¿nos permite una imagen el acceso transparente al modelo como sucede con los espejos o los telescopios? En la historia de la imagen fotográfico-cinematográfica esta discusión se escribe desde Bazin, aunque el problema de la relación entre realidad-representación exista desde casi el comienzo mismo de la filosofía. La posición que se sostiene aquí es intermedia: la transparencia de la imagen depende de cómo se registró y trató, y aunque nunca sea plenamente transparente tampoco es totalmente opaca.

En cuanto a la relación entre la imagen y la imaginación, debemos considerar al espectador involucrado en algún tipo de actividad imaginativa con respecto a la imagen. Pero ¿cuál y cómo sucede? Una respuesta a esta pregunta la ofrece la hipótesis de la participación (Walton, 1990, 2008; Wilson, 1992, 2011). Cuando vemos un film lo que hacemos es imaginarnos que vemos lo que representa la narración ficcional. Dos réplicas al respecto: ¿Por qué algunas películas nos obligan a imaginar algo sin sentido? (Currie, 1995) y ¿desde dónde nos imaginamos los eventos? esto es, ¿existe algún lugar privilegiado para ello? (Wilson, 2011; Carrol, 1996). Por otra lado, ¿esta hipótesis solo se aplica a la ficción o puede ampliarse a imágenes de no-ficción?

2 También podría decirse que la transparencia de la que se habla en el artículo está relacionada con la idea de percepción no epistémica, directa e inmediata, que Dretske defiende en See and Knowing (1969).

3 En Gaut (2010) se recogen siete discusiones diferentes sobre «realismo» en un medio como el cinematográfico: Realismo sobre el contenido, ilusionismo, fotorealismo, realismo ontológico, realismo epistémico, realismo perceptual y realismo de transparencia. La discusión de este artículo se centra solo en el realismo de transparencia. 
Solo trataré aquí el aspecto que relaciona la imaginación y el ver algo como (McGuinn, 2009). Que algo se vea como permite que ante una ficción sea posible enunciar verdades ficcionales. La edición tendría la responsabilidad última de que nuestra percepción sea asistida para que algo lo veamos como y realizar afirmaciones sobre la ficción que sean correctas.

La producción de imagen es un proceso en el cual se pierde gradualmente transparencia desde su registro hasta el caso especial en que ésta forme parte de una ficción. Por ser una cuestión de grado creo insuficiente unificar la transparencia bajo un mismo concepto. Este debe ser modificado según en qué momento de la producción de la imagen nos encontremos, pues afecta a la relación existente entre el modelo, la imagen y la percepción.

Comenzaré por situar el marco general de la discusión sobre la transparencia para después discutir cómo esta propiedad varía (y, por tanto, su sentido debe sufrir alguna modificación) en los distintos momentos de la producción de la imagen. Así, tendríamos transparencia en el registro, de representación, de enunciación y epistémica.

\section{Transparencia}

La transparencia es una propiedad de las imágenes producidas por artefactos de registro mecánico de la realidad. Que sean transparentes significa que se puede ver al modelo a través de las imágenes como si estuviésemos en presencia del mismo. El modelo se representa, esto es, se hace «presente en el tiempo y en el espacio» pues registrado el modelo éste queda fuera de tiempo, «embalsamado» (Bazin, 2004). Solo gracias a la capacidad de registro mecánico de la realidad se puede afirmar que «la fotografía es el objeto en sí mismo» (Seasonske, 1978, 242).

Podemos decir que una imagen que fue producida por un artefacto de captación mecánica de la realidad es transparente porque conserva en mayor grado la información ${ }^{4}$ del modelo original que otros formatos son incapaces de reproducir. Así, la pintura o la escultura, son opacos debido fundamentalmente a la intervención de los estados mentales de los autores de la imagen que degradan la información del modelo. La imagen fotográfico-cinematográfica es capaz de reproducir un mayor grado de información sobre el modelo original. La relación entre la percepción y la imagen es informacional y de dependencia contrafactual.

El teórico del cinematógrafo Andre Bazin $(1985,2000,2004)$ planteó por primera vez la cuestión de la transparencia de la imagen. Fue en unos términos poco sistemáticos, como sucede con el uso que hizo de presencia y representación, o con enunciados como «una imagen es una presentación de aquello que ha sido fotografiado». Es ambiguo pues mezcla aspectos fenomenológicos sobre la experiencia del que mira con la ontología de la imagen. Que se despierten ciertos sentimientos o se aviven recuerdos al contemplar una imagen no implica, necesariamente, que la imagen posea esa propiedad. Si alguien se entristece ante la foto de un familiar que murió no implica que eso sea estar en presencia del modelo; pero aunque Bazin estuviese en lo cierto, ¿la relación causal entre imagen y sujeto que activa esos aspectos fenoménicos debe pasar por asegurar que se está en presencia del modelo?

4 «La información [es] un producto objetivo, cuya generación, transmisión y recepción no requiere, o no presupone en ninguna medida, procesos interpretativos [...] el significado y la constelación de actitudes mentales asociadas que lo manifiestan son productos manufacturados. La información es el material en bruto» (Dretske 1987, pp. 1-2). 
El problema quedará en el aire hasta que Kendal Walton (1984, 1986, 2008) estructure el pensamiento baziniano y defienda que los artefactos que registran mecánicamente la realidad producen imágenes transparentes. Es así porque la imagen:

(1) Nos sitúa en contacto perceptual con el modelo. La imagen fotográfico-cinematográfica es como la imagen de un espejo, un telescopio, un microscopio, etc.

(2) Existe una dependencia contrafactual entre el modelo y el registro de la imagen. El artefacto puede evitar las intenciones del que lo opera.

Antes de entrar en detalle sobre los problemas de esta propuesta debemos evitar la confusión entre transparencia en el sentido de «situar en contacto perceptual» con transparencia en el sentido epistémico. Estos dos conceptos se entrecruzan debido a la vieja idea de que percibir algo del mundo implica conocer algo. Pero también es una vieja tradición el afirmar que percibir algo no es necesariamente conocerlo.

El contenido de una botella de plástico puede permitir ver que en su interior hay un líquido verde, pero si no está convenientemente etiquetado con dificultad podremos saber si se trata de un refresco o de un veneno. Que la botella sea transparente no garantiza que sepamos qué atesora. De forma análoga, si una imagen generada por artefactos mecánicos de registro de la realidad es transparente es porque nos permite ver aquello que retrata, pero debemos cuestionar lo que podemos saber mediante esta imagen. Esto es, en otros términos, cuestionar nuestra capacidad para generar creencias sobre aquello que vemos. Ver el líquido verde en la botella o ver-en-la-imagen la misma botella y líquido sugiere un problema similar de incertidumbre epistémica. Mi interés aquí se centra solo en la transparencia como contacto perceptual.

Que la transparencia sea una propiedad de las imágenes fotográfico-cinematográficas ha sido atacado por dos frentes. Por una parte, los que amplían la propiedad de la transparencia a toda imagen (Lopes, 1996). Por otra, los que creen que toda imagen fotográficocinematográfica es opaca (Currie, 1995; Carrol, 1996).

¿Por qué no ampliar la transparencia a todo tipo de imágenes como a los dibujos hechos a mano? Supongamos que estamos ante una pintura hiperreal y nadie sugiere que sea una pintura, ¿por qué debemos suponer que estamos impedidos por la imagen para ponernos en contacto con el modelo? Por otra parte, ¿por qué es una condición necesaria para dibujar que medien estados mentales? ¿y si nos situamos en otra perspectiva en la cual sea la experiencia (no-conceptual) la que guie al dibujante? (Lopes, 1996).

Dibujar es un acto que difiere considerablemente de activar un dispositivo de registro mecánico de la realidad. Mientras que con una cámara realizo fotografías sin poseer ningún concepto -un niño de un año podría disparar una cámara-, una pintura requiere que el dibujante vea el mundo siendo de una forma determinada, bajo conceptos, deseos y creencias. ¿No resulta inverosímil creer que se puede dibujar un gato sin poseer conceptos? Puedo ver un gato $-\mathrm{o}$ cualquier otra cosa- sin poseer conceptos ${ }^{5}$, pero sin ellos

5 Para la defensa de una percepción no-epistémica ver Drestke 1967, 4 y sig. Aunque siendo justos, también existen posiciones que defienden una conceptualización a priori de la realidad: la mente humana está preparada desde el nacimiento para la conceptualización (McDowell, 1996); sin embargo, esto último difiere considerablemente de lo que Lopes pretende defender. 
difícilmente puedo dibujar un gato. Para ver que $P$, un dibujo, es más oscuro que $O$, el modelo, significa juzgar, ver que... cosa que simplemente ver no hace (Gaut, 2010, 87).

Cierta razón tiene aquel que defiende que no todo debe estar necesariamente conceptualizado para realizar una pintura. Seguro que un niño de entre tres y cinco años carece de conceptos suficientes, pero parece innegable que al menos algún concepto debe ser utilizado -el espacio de representación, las formas que dibuja, las expresiones faciales, los colores, etc. De lo contrario, en lugar de un dibujo serían solo garabatos sin propósito. Esto es suficiente, en principio, para debilitar una defensa de que la transparencia es una propiedad independientemente de cuál sea su forma de producción.

Una de las premisas waltonianas sobre la transparencia consiste en afirmar que existe una conexión causal entre el modelo y el sujeto que ve la imagen. Continuidad esta que asemeja a la que se da cuando se percibe cualquier otro aspecto de la realidad. Los que defienden que toda imagen es opaca sostienen que, primero, la continuidad causal está quebrada y, segundo, que incluso aunque pueda defenderse que existe una continuidad causal entre modelo e imagen, esto no garantiza el contacto perceptual.

Aceptada la hipótesis de que una imagen es transparente cuando está libre de estados mentales, ¿qué es aquello que está causando la imagen? El modelo en sí no puede ser, ya que las cámaras no capturan la esencia de las cosas; por tanto debe ser algo más mundano pero menos intuitivo, como que sea la luz lo que es registrado. Al igual que los ojos captan las distintas frecuencias de la luz donde se codifican los colores, las formas u otras propiedades de los objetos ${ }^{6}$, la cámara realiza un proceso idéntico al convertir la información de los fotones en objetos perceptibles sobre un soporte fotográfico apto. Por tanto, la luz es la causa de la imagen; ésta incide en el objeto y es captada por los mecanismos apropiados de registro, como los ojos o las lentes de la cámara.

Sin embargo, cuando uno observa una imagen, la luz que incide en la imagen es otra bien distinta a la que chocó cuando fue registrada. Al mediar la imagen entre modelo y sujeto, el artefacto mecánico interrumpió la cadena causal entre ambos. Por tanto, la imagen nunca puede ser totalmente transparente, tal y como afirma Gaut (2010).

Creo que esta observación es bastante acertada, pero bajo esta explicación subyace un problema: ver solo puede producirse mediante los ojos y bajo una condiciones determinadas de captación y procesamiento de la luz. Entonces, ¿qué sucede con animales que ven mediante otros sistemas de tratamiento de la información como es el caso del sonar de los murciélagos? (Currie, 1995). Si se crease algún ingenio tecnológico que transforme el oxigeno del entorno en impulsos visuales que captase la piel, ¿es eso ver? Si me injertara un nuevo órgano que genere impulsos eléctricos que me permitan orientarme en el espacio, ¿tampoco vería? Si ver es una clase natural en la que está implicada la relación necesaria entre ojos y fotones, entonces ¿qué sucede con el umwelt de cada especie animal (Uexkull, 2010)? ¿Esas características particulares deben de influir sobre el concepto de ver?

La percepción es bastante sesgada. Registramos la luz y formamos imágenes pero solo somos conscientes de una pequeña cantidad de detalles de lo que se ve (Nöe, 2005, 2006). En cambio, si pudiéramos tomar una instantánea de lo que registran nuestros ojos en un

6 Algunos filósofos defienden que vemos de forma más activa que simplemente esperar a que los fotones choquen contra nuestros ojos. Sobre eso Nöe, 2005. 
momento determinado, con esa imagen seríamos conscientes de la cantidad de detalles que pasaron desapercibidos. En este sentido, es cierto que la imagen, como representación, rompe la continuidad causal, pero ésta suele ser mucho más rica informacionalmente que aquello que se percibió mediante los sentidos. Por tanto, ¿en qué sentido somos más consciente de lo que vemos? ¿al percibir o al mediar la realidad? El problema de los que defienden que la cadena causal está quebrada es obviar que lo que se percibe es la información del modelo.

Atendamos ahora a las objeciones a la segunda condición de transparencia, aquella que supone que la reproducción de la imagen esté libre de estados mentales. Imaginemos que tenemos dos relojes, A y B. Los relojes están en lugares distintos. A emite una señal mediante la cual B siempre registra la hora de A de forma precisa. No media ninguna intención de algún agente entre la señal de A y B. Por tanto si vemos el reloj B ¿podemos afirmar que estamos en contacto perceptual con A? Deberíamos decir que no es así, pues lo que vemos es B y afirmar lo contrario parece descabellado (Currie, 1995). Sería como si al ver en un museo la reproducción de una columna griega dijésemos que estamos viendo la columna real que se encuentra a kilómetros de distancia (Gaut, 2010).

Ambas objeciones se diluyen un poco si pensamos que el caso del reloj y el de la columna son un problema de conservación de la información. En efecto, al ver B no estamos viendo $\mathrm{A}$, pero es que B tampoco es $\mathrm{A}$, incluso aunque ambos relojes se fabricasen en la misma cadena de montaje. B comparte la información que estaría disponible si pudiéramos ver el reloj A. Así, algo de A está en B. Comparten, al menos, que la hora de uno depende contrafactualmente de la hora del otro.

El caso de la columna es ligeramente diferente, la réplica también conserva algunas propiedades del original, pero resulta un tanto complicado afirmar que estamos ante la columna original; si la réplica se manufacturó para que imitase a la original, la columna de réplica fue mediada por ciertos estados mentales que pretendían encarnar la idea de que la columna del museo reproduzca a la columna griega. En este sentido, el problema de las columnas es similar al de la pintura o la escultura: la reproducción es opaca en tanto que han mediado estados mentales en la continuidad entre original y réplica.

$* * *$

En lo que resta de artículo defenderé que una imagen producto de un registro mecánico de la realidad conserva o pierde transparencia según la fase de producción de la imagen.

Es en cada fase del proceso de producción donde se debe cuestionar la transparencia. La imagen se aleja de una transparencia en un sentido pleno conforme desvirtuamos las cualidades informacionales que se preservaron durante su registro. Considero que es en la edición de la imagen donde situaríamos el umbral último de transparencia, pues, como el pintor que encarna pensamientos en la imagen (Scruton, 1981), en la edición se oscurece considerablemente la capacidad de contacto perceptual de la imagen. La edición supone la manipulación intencional de imágenes donde se les da orden y duración; es una forma de agencia que asiste lo que se percibe y articula las verdades ficcionales que se pueden enunciar. En el cine actual prima dirigir la atención de la mirada, algo que se consigue mediante la edición (Gaut, 2010; Bazin, 2004; Bordwell, 1996). 
Para explicar este proceso divido en cuatro sentidos diferentes el concepto de transparencia de la imagen. Cada sentido matiza el significado original de transparencia como contacto perceptual con el objeto representado: (1) Transparencia en el registro, cuando ésta podría ser plenamente transparente; (2) transparencia de representación, cuando se ha generado la imagen y puede ser manipulada conforme a unas intenciones; (3) transparencia de enunciación, aquello que se enuncia sobre una ficción depende de cómo se haya manipulado la imagen y de su relación con (1) y (2); (4) transparencia epistémica.

De estos cuatro sentidos, la transparencia epistémica se queda fuera del estudio. Pertenece a un marco más general que se deriva y rodea el resto de sentidos de transparencias. Se posee transparencia epistémica si al percibir un objeto podemos saber algo sobre lo representado ${ }^{7}$. Aquí se tratará el asunto epistémico solo en su relación con lo que sabemos sobre una ficción mediante la transparencia de enunciación; i.e. cómo una agencia externa a la imagen asiste a la percepción para que se pueda enunciar de forma verdadera lo que se imagina que se ve, pues esto supone que se conoce lo que está sucediendo en la ficción (Wilson, 2011). Pero no hay que confundir transparencia epistémica con transparencia de enunciación: mientras que la verdad ficcional es un problema sobre la imaginación, el de la transparencia epistémica lo es sobre la relación entre imagen y conocimiento del mundo.

\section{Transparencia en el registro}

La transparencia en el registro consiste en que los artefactos de registro mecánico conservan la información sobre la realidad sin que dependan necesariamente de los estados mentales -intenciones, creencias, deseos, etc.- del sujeto que registra la imagen. Así como lo que esté sucediendo en el mundo puede ser indiferente para un dibujante, pues siempre podría ajustar la realidad a sus intenciones, el que maneja una cámara deberá ajustar sus intenciones a la realidad. La imagen que se captará depende contrafactualmente de lo que esté delante del artefacto de registro mecánico de la realidad ${ }^{8}$. El sentido de trasparencia en el registro es el que coincide en mayor medida con lo que se entiende como transparencia de la imagen.

La transparencia en el registro es un asunto artefactual y no tanto un problema sobre la imagen que se va a producir. La consecuencia de que exista la transparencia en el registro puede que sea una imagen transparente, pero lo que se propone con esta categoría de transparencia no es que cuando se esté archivando la realidad se generan imágenes necesariamente transparentes, sino que el máximo grado de transparencia debería darse en este punto de la producción de imagen.

7 Tal vez haya que decir, de forma más específica, que lo que se sucede es que la imagen es capaz de generar una creencia específica sobre lo representado.

8 Que la imagen dependa contrafactualmente del modelo refiere a la teoría de la dependencia contrafactual de la causación de David Lewis (1973): «Un evento $e$ depende contrafactualmente del evento $c$ si y solo si (i) si $c$ ha ocurrido, $e$ habría ocurrido; y (ii) si $c$ no hubiera ocurrido, $e$ no habría ocurrido». Pero existen muchos contraejemplos (conocidos como pre-emtion cases) en los que puede justificarse que $e$ ocurre sin necesidad de que $c$ ocurra. Por esto se dice que la teoría de Lewis describe la causación solo en términos de suficiencia (Paul y Hall, 2013). Podemos decir lo mismo sobre la dependencia entre modelo e imagen, la relación es suficiente (Gaut, 2010). 
Tengamos en cuenta dos cosas. Por un lado, la transparencia en el registro es el momento en el que se está produciendo el traspaso de la información desde la realidad mediante el artefacto de registro. De hecho, aquí no hay aún una imagen de la que se pueda tener experiencia. Por otro, se da a entender con esto que las condiciones para que suceda una transparencia plena solo se dan cuando se está registrando la imagen; una vez la imagen tiene existencia, su transparencia queda mermada.

Al estar la imagen registrándose, hay que considerar la posibilidad de que ésta aún no exista; ese momento en el que se activan los mecanismos de captación del artefacto y aquel espacio-tiempo delante del objetivo está embalsamándose, que diría Bazin. Es en ese instante en los que la imagen está formándose, ese proceso en el que la información se transfiere, cuando los artefactos de registro de la realidad son transparentes. Deviene en paradoja asumir que la imagen sea más transparente cuando aún es inobservable; pero esta propuesto solo quiere dar cuenta de que de que una imagen solo pudiera ser totalmente transparente cuando todavía no se pueda manipular, y no tanto que la imagen solo es transparente en un estado ideal.

Los artefactos de registro mecánico de la realidad ofrecen una «apertura al mundo», en los términos de McDowell (1996), como parece que sucede con los ojos, el oído, la piel o cualquier otro de los órganos y sistemas sensoriales. Estos artefactos son un medio de contacto perceptual con la realidad como lo son otros artefactos que nos asisten en procesos similares: un audífono que modula la escucha, las gafas de sol que filtran la intensidad de la luz, las lentillas que corrigen la visión, etc. Estos artefactos median no tanto para que se perciba la realidad siendo de una forma concreta como que se asista, simplemente, al acceso perceptual. Del mismo modo que, prima facie, el sentido de la vista registra una botella como una botella, una cámara está capacitada para cumplir la misma función.

En cuanto a la posibilidad de una trasparencia plena durante el registro, tengamos en cuenta que manejar una cámara -seleccionar un encuadre, situar los objetos de la realidad, manipular el obturador, la velocidad de captación, uso de filtros en el objetivo, etc.- supone introducir ciertas intenciones en la relación contrafactual con el modelo. Si esto sucede, se debe negar que exista una transparencia total en el registro de imágenes. Pero incluso aunque el artefacto de registro de la realidad funcionase de manera autónoma -y esa autonomía de la cámara implica la carencia de alguna forma de pensamiento- la mecánica del dispositivo posee unas características de fabricación que constriñe la información que puede registrar. Ni todos los niveles de la realidad pueden ser representados, ni todas sus propiedades.

Para que existiese una transparencia en el registro perfecta las condiciones deberían ser ideales: absoluta no intervención que implica autonomía del artefacto y acceso a múltiples capas de la realidad. Condiciones estas que, como podrá suponerse, son solo posibles para los estudiosos de la imagen o para un futuro en el que existan artefactos que lo permitiesen. Pese a estas objeciones, estos artefactos registran y conservarán la información con un nivel de precisión superior, en principio, a cualquier otro formato de registro de la realidad en la que intervengan sujetos con estados mentales. Una pintura siempre sufrirá de opacidad con independencia de lo que la imagen pictórica asemeje a la realidad o la información que conserve porque depende contrafactualmente de las actitudes intencionales del autor de la imagen. 


\section{Transparencia de representación}

Toda imagen generada por un artefacto de registro mecánico de la realidad es una representación. Incluso si se diesen esas improbables condiciones ideales de transparencia que antes se mencionaron, una imagen es una representación de la realidad y nunca la realidad en sí. La discusión en este punto sería si esa representación puede ponernos en contacto perceptual con el modelo.

Los artefactos mecánicos de captación de la realidad representan por semejanza con el modelo (Scruton, 1981), aunque está semejanza sea producto de cómo la información del modelo fue ordenada por el artefacto que genera la imagen. Denomino transparencia de representación a este fenómeno de semejanza entre modelo e imagen que garantizaría la existencia del modelo; i.e. la imagen fotográfico-cinematográfica depende contrafactualmente de la condición de existencia del modelo.

Una vez que se dispone de una representación esta puede manipularse. Editar consiste en manipular la imagen producida. Esto genera, al menos, dos consecuencias inmediatas: (i) disminución de la transparencia de la imagen y (ii) asistir a la percepción para que aquello que se registró se vea de una manera específica; marca la diferencia que supone, por ejemplo, ver a Humphrey Bogart, el actor, o verlo como Rick en la trama de Casablanca. Editar es encarnar intenciones en la imagen.

No es lo mismo un cristal que un espejo. Mientras que el cristal nos permite ver a través suyo (no representa), el espejo nos devuelve una imagen que es representación del modelo. Los defensores de la transparencia de la imagen sostienen que una foto es como el marco de un cristal por el que nos ponemos en contacto con el modelo. Por el contrario, los que defienden la opacidad creen que solo artefactos como un espejo son transparente como el cristal, ya que éstos mantienen la cadena causal entre modelo y percepción (Gaut, 2010, ver arriba).

Sea un espejo, un telescopio o una cámara, cuando accedemos a sus imágenes estos artefactos permiten ver un aspecto de la realidad. La dependencia con lo retratado es contrafactual y exige, por tanto, la condición de existencia del modelo. Lo que se representa en una imagen producida por un artefacto de registro refiere a un aspecto mismo de la realidad. Estas imágenes son como los nombres propios para Saul Kripke, están causadas por el modelo al que refieren. Pero, a diferencia de las personas y sus nombres, modelo e imagen se nos presentan como semejantes.

Si alguien toma una fotografía de la Sagrada Familia, la cámara registrará la Sagrada Familia, mientas que si lo hace estando de paseo frente a la Torre Eiffel difícilmente se registrará la Sagrada Familia. Lo que registre la cámara debería garantizar cierta condición de existencia. En cambio, si se llevase un bloc de notas y un bolígrafo sería indiferente el tener delante la Torre Eiffel y querer dibujar la Sagrada Familia. Es la cámara, al carecer de estados mentales y usar procesos mecánicos de registro, la que obliga a un contacto directo con la realidad que se establece bajo la condición existencia del modelo.

Supongamos que alguien toma una foto de la campiña francesa. Después modifica la imagen e inserta la Sagrada Familia. La composición de la campiña francesa y la Sagrada Familia reduce considerablemente la transparencia de la imagen. Esto no sucede porque 
campo e iglesia carezcan de existencia, sino porque se encarnaron las intenciones del que la manipuló para que se vea siendo de una forma determinada.

La percepción, como tratamiento de la información sensorial, representa la información siendo de una forma determinada. Esto es conocido como experiencia perceptual (Montague, 2009). A lo largo de este artículo se usa la expresión percepción como experiencia perceptual pues toda experiencia perceptual implica percepción -aunque no sucede al contrario. Aunque habitualmente se perciben las cosas siendo como lo que son- i.e. una silla como una sillala experiencia perceptual puede implicar que se sume la imaginación a la percepción. Para diferenciarlo de la fenomenología de la percepción que implica la experiencia perceptual, se ha denominado a esto ver imaginativo, o, simplemente ver como (McGuinn, 2009) ${ }^{9}$. El proceso perceptual, si seguimos un esquema tradicional, sería tal que: el input de la percepción sería la información sensorial capturada con la visión; la percepción sería proceso cognitivo de tratamiento del input sensorial; y la imaginación, al intervenir en el proceso cognitivo, colabora para que el input sensorial sea visto siendo como.

No se trata de que se haga una inferencia sobre lo que se ve, se oye, se huele, etc. -es un caso bien distinto- o que la percepción se presente bajo una única descripción, sino que lo que se vio, escuchó u olió se percibe siendo de una forma determinada. En el caso específico que estoy tratando, el de la imagen, la imaginación implementa aquello que se ve.

Si me miro al espejo lo que veo es mi representación, pero percibo a un hombre siendo guapo, feo, alto, bajo, gordo, delgado, triunfador, fracasado, simpático, desagradable, etc. Características que no están directamente causadas por la representación sino que se elaboran a partir de esa información y que la imaginación asiste. Algo distinto a realizar una inferencia -aunque puedan hacerse. Ver es contacto directo: veo a $S$; pero puedo representármelo de formas distintas. S como amigo, enemigo, amante, padre, madre, compañero, amenaza, incluso varias categorías a la vez. De forma análoga, lo que la edición le hace a la percepción mediante la imagen es asistirla para que perciba la representación siendo de una forma determinada, algo que es, en cierta medida, diferente a lo que se pudo registrar.

Cuando se altera lo representado puede emerger un sentido muy diferente sobre lo percibido en la imagen ${ }^{10}$. El efecto Kuleshov, descubierto por Lev Kuleshov, teórico del cine y cineasta, trata de demostrar esta hipótesis. Kuleshov editó unas imágenes en las que se veía a un hombre con aspecto indiferente y en su contraplano un ataúd; por otro lado, el plano de una niña y luego el de un plato de sopa. Sin indicación alguna por parte del Kuleshov, el público estaba de acuerdo en atribuir pena al hombre y alegría a la niña. Por tanto, el orden y duración de los planos influía notablemente en cómo se percibe la imagen.

Nótese que pese a que lo representado - un hombre triste o una niña alegre- es producto de la manipulación, la imagen aún conserva la condición de existencia de los modelos. En ese sentido, la imagen preserva la transparencia, pues vemos al hombre, a la niña, al plato de sopa, al ataúd y demás, aunque ahora los veamos como un hombre triste y una niña alegre.

9 «Seeing as is joining or mingling of perception and imagination, in which the two elements can always be distinguished» (McGuinn, 2009, 601).

10 Bazin creía que la edición desvirtuaba lo que la cámara registró. Un cine más real era aquel que se asemejaba a nuestra forma natural de ver los objetos, y no el que usa la edición para asistir, señalar o dirigir la atención. Para una respuesta sobre esto ver Gaut, 2010, pp. 74-77. 


\section{Transparencia de enunciación}

Según la transparencia de enunciación una ficción cinematográfica es transparente cuando podemos enunciar adecuadamente aquello que vemos en una narración de ficción (fílmica) ${ }^{11}$.

Ya que en esta parte me centraré exclusivamente en la ficción cinematográfica cabe preguntarse ¿puede existir una transparencia de enunciación sobre una imagen no-ficcional? ${ }^{12}$. Algunos filósofos consideran que toda imagen responde a un «imaginarse que», por lo que una imagen estaría sujeta siempre a ciertas condiciones sobre lo que se podría decir o no decir acerca de esta. Pero este problema compete en mayor medida a lo que llamé transparencia de representación. La transparencia de enunciación, tal y como aquí se entiende, plantea un problema bien distinto: cómo una imagen condiciona aquello que puede decirse sobre ésta cuando se inserta en una ficción.

Según la terminología de Kendall Walton (1990) y George Wilson (1992, 2011) enunciaríamos la transparencia conforme a aquello que estamos imaginándonos que vemos cuando se accede a las imágenes del film; podría, así, enunciarse con propiedad si lo que se percibe es verdadero o falso según sea lo representado ${ }^{13}$. Cuando alguien está ante el final de Casablanca (Michael Curtiz, 1942), sería verdadero afirmar que está imaginándose a Rick despidiéndose de Ilsa en un aeródromo, y falso que está imaginándose a dos elfos partir hacia los Puertos Grises. Pero, si damos crédito a la línea trazada por Walton y Wilson, también sería verdadero afirmar que esta persona está imaginándose a Humphrey Bogart e Ingrid Bergman en un decorado. El registro y representación de imágenes exige la condición de existencia de los modelos, pero en principio, la narración sobre el devenir de Rick e Isla, como personajes de ficción en una ficción, es ajena a la captación de imágenes. ¿Podemos decir que existen dos condiciones de verdad, una orientada a las personas a las que refieren las imágenes y otra a los personajes de la ficción sobre lo representado? ¿Cómo es que vemos a Rick e Ilsa y no a Humphrey Bogart e Ingrid Bergman, o acaso vemos a los dos simultáneamente -los reales y los ficcionales?

Entre ver a Humphrey Bogart y ver como Humphrey Bogart es Rick debemos justificar el hecho de que veamos a Rick en lugar del actor que lo interpreta, pues Humphrey Bogart es un ser humano con existencia mientras que Rick es ficcional.

En el juego de producción de imagen se ha introducido un elemento nuevo, el hacer creer al espectador ciertas características que no están en el modelo. Esto supone un detrimento de la transparencia en favor de la narración ficcional. El editor sería el último umbral en las distintas fases de la producción de la imagen entre una conexión (gradualmente) transparente con los modelos y la intrusión de estados mentales con la intención de narrar. De otra forma, la edición es el último asistente del ver como. Es la edición,

11 Aclaro que esta no es una nueva definición de transparencia, sino que, como el resto de transparencias expuestas, matiza el significado original del término y depende de condiciones diferentes.

12 Existe una discusión sobre si existen marcas sintácticas, semánticas o formales para diferenciar un discurso ficcional de otro que no lo sea (Alcaráz, 2013). En este artículo pasaré por alto por esta cuestión sobre lo ficcional. Pensaremos, en principio, que un espectador identifica -aunque no se especifique cómo -que se encuentra ante una ficción. Sobre el debate: Walton, 1990; Currie, 1991; Lamarque y Olsen, 1994; inter alia.

13 Ver nota al pie 8. 
como manipulación de representaciones, la que asiste a que en el espectador se imagine una determinada cosa -lo representado -, y no solo lo que se registró (Scruton, 1981).

Si se observa un cuadro llamado Sileno en el que se ha dibujado a un vagabundo borracho debemos entender que la intención del dibujante ha sido representar al vagabundo como Sileno. El pensamiento ficcional está siendo encarnado en la representación como condición misma de la existencia de la imagen, esto es, la intención de que se vea a un vagabundo borracho como Sileno. ¿Sucede lo mismo con la fotografía? No, pues la condición principal para el registro trasparente de la fotografía no es la intención de representar, sino la existencia del modelo.

Supongamos que alguien que pasea con sus amigos señala con el dedo a un vagabundo borracho y dice «iSileno!» ¿Qué sucedió? El acto de apuntar con el dedo trata de introducir al vagabundo en una representación de tal modo que sus amigos puedan verle como Sileno. El que señala les está invitando a percibir de una manera determinada al vagabundo. En la producción de la imagen la cámara es el dedo que señala. La edición es la que encarna el pensamiento ficcional en imágenes e introduce a los espectadores en la ficción.

No es cierto, como afirma Scruton $(1981,588)$, que todos los elementos representacionales del pensamiento se den antes de la toma de la imagen. Puede dejarse unas imágenes a alguien sin ninguna guía específica ni instrucciones y que al editarlas esta persona le otorgue duración y orden de tal forma que expresen una intención representacional. La edición encarna pensamientos en la imagen en cada decisión que altere el material del que se disponga.

$$
* * *
$$

La terminología de ver y ver como funciona a la hora de explicar por qué lo que vemos lo vemos siendo de una forma determinada ${ }^{14}$. En la discusión sobre la experiencia cinematográfica estos términos devinieron en lo que vemos y lo que estamos imaginándonos que vemos.

Cuando se está ante un medio representacional se realiza un ejercicio en el cual nos imaginamos que vemos lo representado. Es lo que Walton (1990) llama juego de hacer-creer [make-believe] en el que los objetos materiales -los cuadros, las fotos, la pantalla de cine, etc.- sirven de utillería [props] y apuntadores [prompters] para el ejercicio de la imaginación. Sucede que cuando vemos una fotografía o una pintura nos imaginamos que vemos al modelo ${ }^{15}$. La foto, la pintura, la película es la que nos catapulta hasta la interacción de la imaginación con lo que el objeto representa. Estaríamos entrando, según Walton, en el territorio de los mundos de ficción y de las verdades ficcionales.

14 Sobre ver y ver como, Budd (1984) Wittgensttein's Philosophy of Psychology. London: Routledge; Scruton (1974) Art and imagination. London: Methuen; Wollheim (1980) Arts and its objects. Cambridge: Cambrdge University Press; McGuinn (2009) «Imagination», Oxford Handbook of Philosophy of Mind. Oxford: OUP.

15 Imaginar se entiende como un habilidad del pensamiento, distinta a percibir cuyas condiciones de cumplimiento son específicas. «Imagining (proposal imagining) like (proposal) believing or desiring, is doing something with a proposition one has in mind.» Walton $(1990,20)$ contrapone imaginar a creencia y verdad a ficción. De este modo se presentan dos pares [imaginación-ficción] y [creencia-verdad]. Cada par relaciona sus términos y se pueden imaginar malentendidos o haber creencias falsas. Creer tampoco es imaginar-que, al igual que imaginar y percibir son cuestiones diferentes (McGuinn, 2009, 603). 
Supongamos que se tiene un dibujo de Frodo Bolsón. Frodo es un hobbit, un ser de aspecto antropomorfo, de orejas puntiagudas, más bajitos que media que los humanos y con pies exageradamente grandes y peludos. Los hobbits no se dan en nuestro mundo, como los unicornios o las montañas de oro; así, tenemos la certeza de que el dibujo de Frodo es producto de los estados mentales del dibujante. Pero que sea un personaje de ficción es indiferente; si se tratase del dibujo de un caballo en lugar del de un hobbit estaríamos ante el mismo problema: ninguno de los dos necesita existir como condición para ser dibujados. Al verlo estamos imaginándonos que vemos al hobbit Frodo, pues esa era la intención encarnada en el papel de aquel que lo dibujó -incluso aunque no sepamos que se trata del hobbit Frodo Bolsón.

Pensemos que en lugar de un dibujo de un hobbit tuviésemos una fotografía de Frodo Bolsón de la película The Lord of the Rings (Peter Jackson, 2001). En efecto, seguiríamos sin contacto perceptual con Frodo Bolsón - pues Frodo no existe. Veríamos a Elijah Wood, el chico que lo interpreta, caracterizado como el hobbit llamado Frodo Bolsón en el decorado de un volcán y, de manera simultánea, estamos imaginándonos que vemos a Frodo Bolsón en el Monte del Destino. Nos estamos poniendo en contacto perceptual con un primer nivel en el que vemos al actor mientras que a su vez, en un segundo nivel, se nos asiste a entrar en la ficción representada; el segundo nivel es el que nos permite afirmar ciertas verdades ficcionales sobre la imagen, como sería «estoy imaginándome que veo a Frodo en el Monte del Destino».

Para Walton, este juego de imaginarnos que estamos viendo también se da en cualquier otro tipo de imagen fotográfica que no represente un objeto o situación que implique la agencia de un narrador como pudiera ser una foto de graduación o la de la Sagrada Familia, con la excepción de que en este tipo de imágenes existe una correlación entre lo que vemos y lo imaginamos que vemos $(2008,127)$. Pero ¿por qué motivo nos estamos imaginándonos que vemos y no, simplemente que veo? Entendería que se den las dos cosas cuando nos enfrentamos a una ficción, pero ¿por qué debería sucederme el mismo efecto cuando no hay mediación entre la imagen y una narración que la conduzca?

Wilson $(1992,2011)$ cuestiona eso mismo. Cuando en la imagen se encarnaron pensamientos que asistan a imaginarse algo de una manera particular hay una diferencia entre lo que vemos (Elijah) y aquello que vemos en la ficción (que esa persona representa a Frodo Bolsón); así, no siempre que vemos una imagen producida por un artefacto de registro mecánico de la realidad se nos impone que imaginemos que vemos que $p$. Solo cuando una intención ficcional manipula la imagen con el propósito de que se vea como, puede la imagen ser vista como. Así en la ficción de El señor de los anillos, decimos que se ve a Elijah pero vemos a Elijah como Frodo, pues la edición asiste a que percibamos imaginativamente esta situación.

De este modo, ante una imagen no se tiene libertad absoluta imaginarse lo que se quiera (Wilson, 1992; Scruton, 1981) pues la imagen y la agencia que articula la narración asistiría lo se podría imaginarse que se ve. Pero tampoco implica, necesariamente, como afirma Wilson que el responsable de la narración de ficción prescriba aquello que se puede decir sobre el film: no todos los aspectos de la imagen pueden ser controlados o fijados desde una supuesta entidad presente tras la imagen. 


\section{Las marcas de lo ficcional}

He propuesto aquí que una imagen fotográfico-cinematográfica producida por un artefacto de captación mecánica de la realidad no es transparente como Walton afirma, ni opaca como mencionan sus críticos. La transparencia de la imagen depende del momento de su producción, así como de la manipulación a la que se ve sometida. Incluso cuando no sepamos qué se está viendo o la imagen esté dentro de una narración ficcional, esta conserva algo de la información original del modelo. Dado esto, podemos afirmar que estamos en contacto perceptual con, al menos, alguna de las características del modelo. Decimos que percibimos una iglesia ante una foto de la Sagrada Familia -aunque no sepa su nombre -o que vemos a Elijah Wood aunque nuestra percepción esté asistida para que le veamos como un hobbit de El señor de los anillos.

Por supuesto, quedan abiertas muchas cuestiones alrededor de lo que se propuso. ¿De qué manera una meta-imagen afectaría a los umbrales de transparencia? ¿No se exagera el peso de la edición en el modo en que se encarnan ideas en un medio como el cinematográfico, cuando, por ejemplo, un movimiento de cámara también asiste a la percepción? ¿Cómo afecta la imagen digital a la transparencia? (Gaut, 2010) Pero existe una cuestión a la que dedicar estas últimas líneas: las marcas de lo ficcional.

En el campo literario se discute sobre si existen o no marcas semánticas, léxicas o formales que diferencien claramente lo ficcional de lo real (Alcaráz, 2013). Por el momento parece que el consenso mayoritario es que no existen como tales, solo gracias al contenido o mediante elementos externos, como es comprar un libro en una sección de ficción, podemos diferenciar entre ficción o no-ficción. Algo similar sucede al ver una ficción cinematográfica. Por tanto, no es tan evidente, como he defendido, que al editar una imagen para insertarla en una narración de ficción ésta asista transparentemente la enunciación de verdades ficcionales, pues, para empezar, ¿cómo puede enunciarse una de estas verdades si ni siquiera puedo distinguir claramente ficción de no-ficción? La elección del plano, los movimientos de cámara, o los cortes de edición ayudan a diferenciar entre ficción y no-ficción, pero no siempre ni en toda circunstancia.

Es cierto que Walton solventa estas cuestiones ampliando su imaginarse viendo a todo tipo de imagen, pero resulta insuficiente en cuestiones de transparencia. Si recibo un video con una amenaza de bomba producido como si fuera un blockbuster, ¿basta decir que como siempre me imagino que veo que $p$ y como, además, toda imagen es siempre transparente, es suficiente para actuar y dejo de lado si la imagen es real o ficticia? Creo que no. Aunque en este caso se mezclen asuntos epistémicos, la ontología de la formación de la imagen ficcional debería poder aclararnos algo en este aspecto.

\section{Bibliografía}

Alcaraz, M. J. (2013), «Arte, ficción y verdad» en: Estética. Francisca Pérez Carreño (ed.) Madrid: Tecnos.

Bazin, A. (1985), «Three Essays On Widescreen». Velvet Light Trap: A Critical Journal Of Film \& Television. 21, pp. 8-16.

Bazin, A. (2000), «Andre Bazin On Film Technique: Two Seminal Essays». Film Criticism. 25, 2, pp. 48-78. 
Bazin, A. (2004), ¿Qué es el cine? Madrid: Rialp.

Bordwell, D. (1996), La narración en el cine de ficción. Barcelona: Paidos.

Bordwell, D. (2002), «Intesified Continuity». Film Quaterly, 55, 3, pp. 16-28.

Carrol, N. (1995), «Towars An Ontology Of The Moving Image» En Cynthia A. Freeland y Thomas E. Warterberg (Eds.) Philosophy And Film. London: Routledge.

Carrol, N. (1996), «Defining The Moving Image» en Theorizing The Movie Image. Nueva York: Cambridge University Press, pp. 49-74.

Currie, G. (1995), Image And Mind: Film, Philosophy, And Cognitive Science. Cambridge: Cambridge University Press.

Currie, G. (2010), Narrative \& Narrators. Oxford: Oxford University Press.

Cutting, J. (2005), «Perceiving Scenes In Film And In The World». En Anderson, J. y Anderson, B. (Eds.) Moving Image Theory, Ecological Considerations. Illinois: Souther Illinois University Press.

Dretske, F.I. (1969), Seeing and Knowing. Chicago: University of Chicago Press.

Dretske, F.I. (1987), Conocimiento e información. Barcelona: Salvat.

Gaut, B. (1997), «Analytic Philosophy Of Films: History, Issues, Prospects.» Philosophical Books, Vol. 38, 3, pp. 145-156.

Gaut, B. (1998), «Imagining, Interpretating, And Film». En Philosophical Studies, 89, pp 331-341.

Gaut, B. (2010), A Philosophy Of Cinematic Art. Cambridge: Cambridge University Press.

Lamarque, P y Olsen, S.H. (1994), Truth, Fiction and Literature. Oxford: Clarendon Press.

Lewis, D. (1973), Counterfactuals. Massachusetts: Blackwell.

Lopes, D. M. (1996), Understanding Pictures. Oxford:Oup.

McDowell, J. (1996), Mind and world. Harvard: HUP.

Mcginn, C. (2009), «Imagination». En Oxford Handbook Of Philosophy Of Mind, Brian P. Mclaughlin, Ansgar Beckerman y Sven Walter. Oxford:Oup.

Montague, M. (2009), «The Content Of Perceptual Experience». En Oxford Handbook Of Philosophy Of Mind, Brian P. Mclaughlin, Ansgar Beckerman y Sven Walter. Oxford: Oup.

Nöe, A. (2005), «What does change blindness teach us about consciousness?» En Trends in Cognitive Science, v.9, 5, 218.

Nöe, A. (2006), Perception In Action. Mit: MUP.

Scruton, R. (1981), «Photography And Representation» En Critical Injury, V.7, 3, pp. 577603.

Sesonske, A. (1974) «Aesthetics Of Film, Or A Funny Thing Happened On The Way To The Movies» En Journal Of Aesthetics And Art Criticism 33, 1, pp. 51-57.

Sesonske, A. (1978), «Andre Bazin By Dudley Andrew». En The Journal Of Aesthetics And Art Criticism. Vol. 37, 2, pp. 241-243.

Sesonske, A. (1980), «Time And Tense In Cinema». En The Journal Of Aesthetics And Art Criticism, 38, 4, pp.419-426.

Walton, K. L. (1980), «Appreciating Fiction», en Dispositio, 13-14, pp. 1-18.

Walton, K. L. (1984), «Transparent Pictures: On The Nature Of Photographic Realism», en Critical Enquiry, 11, pp. 246-277.

Walton, K. L. (1986), «Looking Again Through Photograph: A Response To Edwin Martin» en Critical Inquiry, 12, 4, pp.801-808. 
Walton, K. L. (1990), Mimesis As Make-Believe, On The Foundations Of The Representational Arts. Massachusset: Harvard University Press.

Walton, K. L. (2008), Marvellous Images. New York: Oxford University Press.

Wilson, G. M. (1992) Narration In Light. New York: Johns Hopkins University Press.

Wilson, G. M. (2011), Seeing Fictions. Oxford: Oxford University Press.

Uexkull, J. (2010), «The Theory Of Meaning». En Essential Readings In Biosemiotics Anthology And Commentary Spinger: New York. 